\title{
Produção de anticorpos policlonais para lectina de hemolinfa de Anticarsia gemmatalis
}

\section{Production of polyclonal antibodies for lectin from Anticarsia gemmatalis hemolymph}

\author{
Fernanda Bovo ${ }^{1}$; Rogério Fernandes de Souza²; Daniel R. Soza-Gomez ${ }^{3}$; Flávio \\ Moscardi³; Fábio Eduardo Paro ${ }^{4}$; Eiko Nakagawa Itano5; Mario Augusto Ono ${ }^{5}$.
}

\section{Resumo}

\begin{abstract}
A lagarta de Anticarsia gemmatalis promove extensos danos na cultura da soja e seu controle é geralmente baseado na aplicação de inseticidas químicos. Devido aos riscos à saúde humana, animal e ao meio ambiente, métodos alternativos de controle tem sido desenvolvidos como o bioinseticida Baculovirus anticarsia. Há relatos de desenvolvimento de resistência em populações de A. gemmatalis submetidas, em laboratório, ao tratamento com baculovirus durante várias gerações. Os insetos apresentam mecanismos elaborados de proteção contra agentes infecciosos, como as lectinas, que atuam como moléculas de reconhecimento. Assim, o objetivo deste estudo foi desenvolver anticorpos policlonais para lectina de $A$. gemmatalis. A atividade de lectina de hemolinfa de lagartas de $A$. gemmatalis foi avaliada frente a hemácias humanas, de coelho, camundongo, carneiro e boi em ensaio de hemaglutinação. Apenas as hemácias de bovino não foram aglutinadas pela lectina. As hemácias de coelho apresentaram maior reatividade com a lectina (1:512) e portanto os anticorpos policlonais foram produzidos em coelho imunizado com hemácias autólogas sensibilizadas com lectina. O anticorpo anti-lectina apresentou título de 1:8 em reação de precipitação em gel. Assim, nesse estudo foi possível produzir anticorpos para lectina de A. gemmatalis sem necessidade de emprego de técnicas dispendiosas de purificação.

Palavras-chave: Anticarsia gemmatalis. Hemolinfa. Lectina. Anticorpo policlonal.
\end{abstract}

\begin{abstract}
The velvet bean caterpillar Anticarsia gemmatalis promotes extensive damage to soybean and is controlled frequently by chemical insecticides. Due to risks to human and animal health as well as the environment, new approaches were developed to A. gemmatalis control such as the bioinsectide Baculoviru anticarsia. The development of resistance in A. gemmatalis populations treated along several generations with $B$. anticarsia was reported under laboratory conditions. The insects show complex mechanisms against microorganism infection, such as the lectins, that work as recognition molecules. The aim of this work was to develop polyclonal antibodies to A. gemmatalis lectin. The lectin activity in A. gemmatalis caterpillar hemolymph was evaluated using erythrocytes from human, rabbit, mouse, sheep and cow. Only bovine erythrocytes were not agglutinated by lectin. The rabbit erythrocytes showed stronger reactivity (1:512). Therefore the polyclonal antibodies were raised in rabbit immunized with autologous erythrocytes sensitized with lectin. The antibody to lectin showed a titer of 1:8 in immunodiffusion test. In this study we described a simple method for antibody production against hemolymph lectin without expensive purification techniques.
\end{abstract}

Key words: Anticarsia gemmatalis. Hemolymph. Lectin. Polyclonal antibod.

\footnotetext{
${ }^{1}$ Farmacêutica-Bioquímica pela Universidade Estadual de Londrina, Mestranda do Programa de Mestrado em Patologia Experimental, UEL.

${ }^{2}$ Docente do Depto. de Biologia Geral, Universidade Estadual de Londrina.

${ }^{3}$ Pesquisadores da Empresa Brasileira de Pesquisa Agropecuária, Embrapa Soja, Londrina.

${ }^{4}$ Assistente de Pesquisa da Empresa Brasileira de Pesquisa Agropecuária, Embrapa Soja, Londrina.

${ }^{5}$ Docentes do Depto. de Ciências Patológicas, UEL.E-mail: marioono@uel.br.
} 


\section{Introdução}

A lagarta de Anticarsia gemmatalis causa extensos danos à lavoura da soja e é considerada a principal praga desfolhadora dessa cultura (MOSCARDI, 1989). O seu controle é feito basicamente pela aplicação de inseticidas químicos, que apresentam desvantagens, como alto custo, e danos ao meio ambiente e à saúde humana e animal.

Um método de controle alternativo, que vem despertando interesse crescente devido ao baixo custo e menor agressão ao ambiente, baseia-se na utilização de inseticidas biológicos, ou seja, de microrganismos patogênicos para insetos, como vírus (TINSLEY, 1979; MOSCARDI, 1999), bactérias (GILL; COWLES; PIETRANTONIO, 1992; NAVON, 2000) e fungos (FERRON, 1978; HEGEDUS; KHACHATOURIANS, 1995).

O vírus da poliedrose nuclear, Baculovirus anticarsia, é utilizado no controle da lagarta da soja. Os insetos são infectados quando ingerem alimento contaminado com o vírus. Ao atingir o trato intestinal, devido ao $\mathrm{pH}$ alcalino, os poliedros do baculovírus são dissolvidos e as partículas virais são liberadas para posteriormente infectar as células. As lagartas infectadas sofrem redução na alimentação e na mobilidade, apresentam uma coloração branco-leitosa, e morrem aproximadamente 7 dias após a infecção (MOSCARDI, 1983; BATISTA; CRUZ, 1988).

Nas safras de 1980/81 e 1981/82, a EMBRAPASoja introduziu no Estado do Paraná um programa de controle biológico da $A$. gemmatalis utilizando $B$. anticarsia (MOSCARDI, 1989). Posteriormente, a tecnologia foi difundida para outros Estados do Brasi,le também para outros países da América do Sul, como Argentina, Paraguai e Uruguai (SOSA-GÓMEZ; MOSCARDI, 1991). No Brasil, na safra de 1989/90, cerca de 1 milhão de hectares de cultura de soja foram tratados com baculovírus (MOSCARDI, 1990).

Embora ainda não haja relatos de desenvolvimento de resistência ao baculovírus no campo, é possível ocorra o desenvolvimento de populações localizadas de $A$. gemmatalis resistentes ao B.anticarsia. No entanto, devido à migração de populações suscetíveis (FUXA et al., 1993), essas populações não estão sendo detectadas.

Adicionalmente, há relato de desenvolvimento de resistência em populações de $A$. gemmatalis em condições de laboratório, quando elas são submetidas ao tratamento com baculovirus por várias gerações (ABOT, 1993).

Os insetos possuem mecanismos elaborados de proteção contra agentes infecciosos (BOMAN; HULTMARK, 1987; DUNN, 1986). Após a infecção por microrganismos ocorre um aumento na concentração de determinadas proteínas da hemolinfa de insetos (ANDERSON; COOK, 1979; ASHIDA, 1971; SUMIDA et al., 1992; GILLESPIE; KANOST, 1997), como as lectinas (KOMANO; MIZUNO; NATORI, 1981; WHEELER; STUART; HAPNER, 1993; YU; KANOST, 2000).

Pendland e Boucias (1985) relataram aumento no título de lectina em hemolinfa de $A$. gemmatalis infectadas com o fungo Nomureae rileyi, enquanto que Mori et al. (1989) observaram elevação nos níveis de lectina na hemolinfa de lagartas de Bombyx mori infectadas com vírus da poliedrose citoplasmática, sugerindo que as lectinas apresentam um efeito protetor contra os agentes infecciosos.

É de extrema importância a caracterização das moléculas envolvidas nos mecanismos de proteção dos insetos para melhor compreender o desenvolvimento de resistência aos inseticidas biológicos. Assim, este estudo teve como objetivo produzir anticorpos policlonais para lectina de $A$. gemmatalis.

\section{Materiais e métodos}

Manutenção e cria das colônias de $A$. gemmatalis

As lagartas de A. gemmatalis foram mantidas com dieta artificial no Centro Nacional de Pesquisa da Soja - EMBRAPA como descrito em HoffmannCampo, Oliveira e Moscardi (1985). 


\section{Coleta de hemolinfa de $A$. gemmatalis}

A hemolinfa de $A$. gemmatalis foi coletada de largartas de $4^{\circ}$ instar pela punção de uma das pernas com auxílio de uma micropipeta. Após a coleta, a hemolinfa foi transferida para tubo de polipropileno, mantido a $4{ }^{\circ} \mathrm{C}$, com alguns cristais de feniltiouréia para inibição das fenoloxidases. Após centrifugação a 10.000 x g para remoção de células, o sobrenadante foi estocado a $-20^{\circ} \mathrm{c}$ até o momento do uso.

\section{Obtenção de hemácias}

Foram coletadas amostras de sangue por meio de punção venosa ou punção intra-cardíaca de carneiro, coelho, camundongo, cobaia, bovino e humano (tipos $\mathrm{O}, \mathrm{A}, \mathrm{B}$ e $\mathrm{AB}$ ). As amostras foram transferidas assepticamente para tubos com solução de Alsever estéril e, após a homogeneização, foram estocadas à $4{ }^{\circ} \mathrm{C}$ por até 3 semanas.

\section{Ensaio de atividade lectina em hemolinfa de A. gemmatalis}

O ensaio de atividade de lectina foi realizado por meio de aglutinação de suspensão de hemácias a 2 \% em PBS, pH 7,2. Foram realizadas diluições em série de hemolinfa de 1:2 a 1:1024 em microplacas de 96 cavidades, com fundo em "v", em seguida foram adicionadas às cavidades $50 \mathrm{~m} ð 1$ de suspensão de hemácias de cada uma das espécies, em duplicata. A leitura foi realizada após 2 horas de incubação à temperatura ambiente.

As hemácias de cada espécie foram analisadas pelo menos duas vezes no ensaio de aglutinação.

Para a avaliação do efeito de carboidratos sobre a atividade de lectina, o ensaio de aglutinação com hemácias de coelho foi realizado na presença e na ausência de glicose, galactose, lactose e maltose na concentração de $0,2 \mathrm{M}$.

\section{Obtenção de anticorpo policlonal contra lectina de A. gemmatalis}

Uma suspensão de hemácias de coelho a $2 \%$ em PBS, pH 7,3, foi incubada com hemolinfa de $A$. gemmatalis por 1 hora à temperatura ambiente $\mathrm{e}$ lavada três vezes com salina a $4^{\circ} \mathrm{C}$. As hemácias sensibilizadas com lectina foram ressuspensas em salina e homogeneizadas com adjuvante completo de Freund (Sigma, Saint Louis) e inoculadas, por via subcutânea, no mesmo coelho do qual as hemácias haviam sido coletadas. Uma segunda dose foi administrada pela mesma via, porém com hemácias sensibilizadas homogeneizadas com adjuvante incompleto de Freund (Sigma, Saint Louis). Dez (10) dias após a segunda dose, o coelho foi sangrado e o soro obtido foi analisado por reação de precipitação em gel.

\section{Reação de precipitação em gel}

Lâminas de microscopia 26 x $76 \mathrm{~mm}$ foram adicionadas de 3,5 ml de solução de agar 1,0\% em PBS e após gelificação foram feitos os orifícios (6 periféricos e 1 central). As diluições do soro de coelho (1:2 a 1:64) foram pipetadas nos orifícios periféricos e a hemolinfa (pura) foi pipetada no orifício central. As lâminas foram incubadas em câmara úmida por 24 horas e, após a lavagem em salina, foi realizada a coloração com Azul de Coomassie.

\section{Resultados e discussão}

Foi observada uma grande variabilidade na reatividade da lectina com hemácias das diferentes espécies de animais avaliadas neste trabalho. Os títulos mais elevados de aglutinação foram observados com hemácias de coelho (1:512) e humanas tipo O (1:128), enquanto as hemácias bovinas não foram aglutinadas nas condições do experimento (Tabela 1). Pendland e Boucias (1985) também observaram maior atividade da lectina de A. gemmatalis sobre hemácias de coelho. 
Tabela 1. Aglutinação de hemácias de diferentes espécies por lectina de hemolinfa de $A$. gemmatalis

\begin{tabular}{cc}
\hline HEMÁCIAS & TíTULO \\
\hline coelho & $1: 512$ \\
humana tipo O & $1: 128$ \\
humana tipo AB & $1: 64$ \\
humana tipo B & $1: 64$ \\
humana tipo A & $1: 32$ \\
cobaia & $1: 16$ \\
camundongo & $1: 16$ \\
carneiro & $1: 8$ \\
bovina & n.a. \\
\hline
\end{tabular}

Para avaliar os carboidratos importantes na interação da lectina com hemácias de coelho, foi realizado um ensaio de inibição da aglutinação com diferentes carboidratos e ocorreu inibição com galactose e lactose, que promoveram uma diminuição do título de aglutinação (Tabela 2), conforme foi observado por Pendland e Boucias (1985) em estudo com hemolinfa de larvas de $A$. gemmatalis infectadas com o fungo entomopatogênico Nomurea rileyi.

Tabela 2. Efeito de carboidratos sobre a aglutinação de hemácias de coelho por lectina de hemolinfa de $A$. gemmatalis

\begin{tabular}{ccc}
\hline CARBOIDRATO & $\begin{array}{c}\text { TítUlO SEM } \\
\text { CARBOIDRATO }\end{array}$ & $\begin{array}{c}\text { TítULO COM } \\
\text { CARBOIDRATO }\end{array}$ \\
\hline galactose & $1: 512$ & $1: 128$ \\
lactose & $1: 512$ & $1: 128$ \\
maltose & $1: 512$ & $1: 512$ \\
glicose & $1: 512$ & $1: 512$ \\
\hline
\end{tabular}

Considerando que as hemácias de coelho apresentaram maior reatividade com a lectina, a produção dos anticorpos policlonais foi feita a partir da imunização de coelho com hemácias autólogas sensibilizadas com lectina.

O soro imune anti-lectina apresentou título de 1:8 em reação de precipitação em gel, com apenas uma linha de precipitação (Fig. 1), sugerindo que atividade de lectina é constituída de apenas uma molécula ou, ainda, que há uma molécula predominante que encontra-se em maior concentração na hemolinfa.

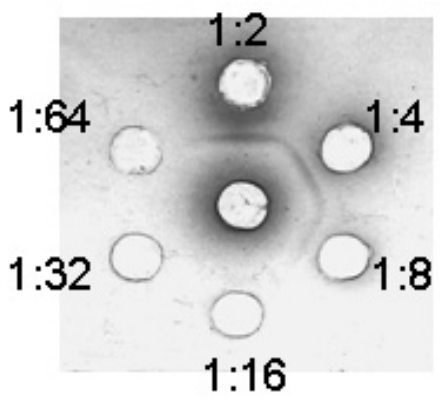

Figura 1. Reação de precipitação em gel com o soro de coelho anti-lectina de $A$. gemmatalis. As diluições do soro de 1:2 a 1:64 foram pipetadas nos orifícios externos e a hemolinfa pura no orifício interno.

Neste estudo, demonstramos um método simples e eficiente de produção de anticorpos policlonais para lectina de hemolinfa de A. gemmatalis, sem a necessidade de purificação prévia da lectina para imunização. O processo de purificação exige técnicas elaboradas e de custo elevado como as cromatografias de filtração em gel (CHUNG; OURTH, 2002), de troca-iônica (UMETSU; KOSAKA; SUZIKI, 1984), cromatografia de afinidade (CHEN et al., 1999) e cromatografia de alta eficiência (WANG; JIANG; KANOST, 2001; CHUNG; OURTH, 2002).

Anticorpos policlonais são ferramentas valiosas para a detecção, caracterização e quantificação de biomoléculas. Os anticorpos anti-lectina poderão ser utilizados para caracterização da possível atividade protetora contra o baculovirus ou ainda para purificação da lectina por cromatografia de imunoafinidade.

\section{Agradecimentos}

Os autores agradecem à Pró-Reitoria de Pesquisa e Pós-Graduação da UEL pela concessão de auxílio financeiro para a realização deste trabalho. 


\section{Referências}

ABOT, A. R. Avaliação da resistência de Anticarsia gemmatalis Hubner 1818 (Lepdoptera: Noctuidae) ao seu vírus de poliedrose nuclear. Curitiba: Universidade Federal do Paraná, 1993.

ANDERSON, R. S.; COOK, M. L. Induction of lysozymelike activity in the hemolymph and hemocytes of a insect, Spodoptera eridania. Journal of Invertebrate Pathology, San Diego, v.33, p.197-203, 1979.

ASHIDA, M. Purification and characterization of prophenoloxidase from hemolymph of the silkworm Bombyx mori. Archives of Biochemistry and Biophysics, New York, v.144, p.749-762, 1971.

BATISTA, A. F.; CRUZ, B. P. B. Controle microbiano das pragas da soja. In: CRUZ, B.P.B. Pragas das culturas e controle biológico. Campinas: Fundação Cargill, 1988. p.61-67

BOMAN, H.G.; HULTMARK, D. Cell-free immunity in insects. Annual Review of Microbiology, Palo Alto, v.41, p.103-126, 1987.

CHEN, C.; ROWLEY, A. F.; NEWTON, R. P.; RATCLIFFE, $\mathrm{N}$. A. Identification, purification and properties of a beta1,3-glucan-specific lectin from the serum of the cockroach, Blaberus discoidalis which is implicated in immune defence reactions. Comparative Biochemistry and Physiology B-Biochemistry and Molecular Biology, New York, v.122, p.309-319, 1999.

CHUNG, K. T.; OURTH, D. D. Purification and characterization of apolipophorin III from immune hemolymph of Heliothis virescens pupae. Comparative Biochemistry and Physiology B-Biochemistry and Molecular Biology, New York, v.132, n.2, p.505-514, 2002.

DUNN, P.E. Biochemical aspects of insect immunology. Annual Review of Entomology, Stanford, v.31, p.321-339, 1986.

FERRON, P. Biological control of insect pests by entomogeneous fungi. Annual Review of Entomology, Stanford, v.23, p.409-442, 1978.

FUXA, J. R.; ABOT, A. R.; MOSCARDI, F.; SOSAGÓMEZ, D. R.; RICHTER, A. R. Selection of Anticarsia gemmatalis resistence to NPV, and susceptibility of field populations to the virus. Resistant Pest Management, Michigan, v.5, n.1, p.40-41, 1993.

GILL, S. S; COWLES, E. A.; PIETRANTONIO, P. V. The mode of action of Bacillus thuringiensis endotoxins. Annual Review of Entomology, Stanford, v.37, p.615-636, 1992.

GILLESPIE, J. P.; KANOST, M. R. Biological mediators of insect immunity. Annual Review of Entomolology, Stanford, v.42, p.611-643, 1997.
HEGEDUS, D. D.; KHACHATOURIANS, G. G. The impact of biotechnology on hyphomycetous fungal insect biocontrol agents, Biotechnology Advances, New York, v.13, p.455-490, 1995.

HOFFMANN-CAMPO, C. B.; OLIVEIRA, E. B.; MOSCARDI, F. Criação massal de lagarta da soja (Anticarsia gemmatalis). Londrina: EMBRAPA-CNPSo, 1985. (Documento 10).

KOMANO, H.; MIZUNO, D.; NATORI, S. A possible mechanism of induction of insect lectin. Journal of Biological Chemistry, Bethesda, v.256, p.7087-7089, 1981.

MORI, H.; OHYANE, M.; ITO, M.; IWAMOTO, S.; MATSUMOTO, T.; SUMIDA, M.; MATSUBARA, F. Induction of hemagglutinating activity in the hemolymph of the silkworm, Bombyx mori, infected with cytoplasmic polyedrosis virus. Journal of Invertebrate Pathology, San Diego, v.54, p.112-116, 1989.

MOSCARDI, F. Utilização de Baculovirus anticarsia para o controle da lagarta da soja, Anticarsia gemmatalis. Londrina:EMBRAPA-CNPSo, 1983. (Comunicado Técnico 23).

MOSCARDI, F. Use of viruses for pest control in Brazil: The case of nuclear polyhedrosis virus of the soybean caterpillar, Anticarsia gemmatalis. Memórias do Instituto Oswaldo Cruz, Rio de Janeiro, v.84, p.51-56, 1989.

MOSCARDI, F. Development and use of soybean caterpillar baculovirus in Brazil. In: INTERNATIONAL COLOQUIUM ON INVETEBRATE PATHOLOGY AND MICROBIAL CONTROL, 5., 1990, Adelaide. Proceeding... Adelaide: Society for Invertebrate Pathology, 1990. p.184-187.

MOSCARDI, F. Assessment of the application of baculoviruses for control of Lepidoptera. Annual Review of Entomolology, Stanford, v.44, p.257-289, 1999.

NAVON, A. Bacillus thuringiensis insecticides in crop protection - reality and prospects. Crop Protection, Guildford, v.19, n.8-10, p.669-676, 2000.

PENDLAND, J. C.; BOUCIAS, D. G. Hemagglutinating activity in the hemolymph of Anticarsia gemmatalis larvae infected with the fungus Nomureae rileyi. Developmental and Comparative Immunology, New York, v.9, p.21-30, 1985.

SOSA-GÓMEZ, D.R.; MOSCARDI, F. Microbial control and insect pathology in Argentina. Ciência e Cultura, São Paulo, v.43, p.375-379, 1991.

SUMIDA, M.; ICHIMORI, H.; YUHKI, T.; MORI, H.; MATSUBARA, F. Induction of antibacterial activity in the haemolymph of the silkworm, Bombyx mori, by injection of formalin-treated Escherichia coli K-12 in the anterior and posterior body part of the ligated larvae. Comparative Biochemistry and physiology B- 
Biochemistry and Molecular Biology, New York, v.101, n.1-2, p. 173-178, 1992.

TAKAHASHI, H.; KOMANO, H.; NATORI, S. Expression of the lectin gene in Sarcophaga peregrina during normal development and undr conditions where the defence mechanism is activated. Journal of Insect Physiology, Oxford, v.32, n.9, p.771-779, 1986,

TINSLEY, T.W. The potential of insect pathogenic viruses as pesticidal agents. Annual Review of Entomology, Stanford, v.24, p.63-87, 1979.

UMETSU, K.; KOSAKA, S.; SUZUKI, T. Purification and characterization of a lectin from the beetle, Allomyrina dichotoma. The Journal of Biochemistry; Tokyo v.95, n.1, p.239-245, 1984.
WANG, Y.; JIANG, H.; KANOST, M. R. Expression and purification of Manduca sexta prophenoloxidaseactivating proteinase precursor (proPAP) from baculovirus-infected insect cells. Protein Expression and Purification; Orlando, v.23, n.2, p. 328-37, 2001.

WHEELER, M. B.; STUART, G. S.; HAPNER, K. D. Agglutinating mediated opsonization of fungal blastopores in Melanoplus differencialis (Insecta), Journal of In sect Physiology, Oxford, v.39, p.477-483, 1993.

YU X-Q.; KANOST, M. R. Immulectin-2, a lipopolysaccharide specific lectin from an insect, Manduca sexta, is induced in response to Gram-negative bacteria. Journal of Biological Chemistry, Bethesda, v.275, n.48, p.37373-37381, dez. 2000. 